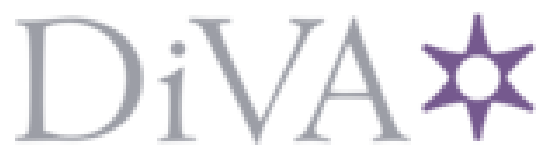

http://www.diva-portal.org

This is the published version of a paper published in Angewandte Chemie International Edition.

Citation for the original published paper (version of record):

Senf, D., Ruprecht, C., Kishani, S., Matic, A., Toriz, G. et al. (2018)

Tailormade Polysaccharides with Defined Branching Patterns:Enzymatic

Polymerization of Arabinoxylan Oligosaccharides

Angewandte Chemie International Edition, : 12163-12168

https://doi.org/10.1002/anie.201806871

Access to the published version may require subscription.

N.B. When citing this work, cite the original published paper.

Permanent link to this version:

http://urn.kb.se/resolve?urn=urn:nbn:se:kth:diva-251376 


\title{
Tailormade Polysaccharides with Defined Branching Patterns: Enzymatic Polymerization of Arabinoxylan Oligosaccharides
}

\author{
Deborah Senf, Colin Ruprecht, Saina Kishani, Aleksandar Matic, Guillermo Toriz, \\ Paul Gatenholm, Lars Wågberg, and Fabian Pfrengle*
}

\begin{abstract}
The heterogeneous nature of non-cellulosic polysaccharides, such as arabinoxylan, makes it difficult to correlate molecular structure with macroscopic properties. To study the impact of specific structural features of the polysaccharides on crystallinity or affinity to other cell wall components, collections of polysaccharides with defined repeating units are required. Herein, a chemoenzymatic approach to artificial arabinoxylan polysaccharides with systematically altered branching patterns is described. The polysaccharides were obtained by glycosynthase-catalyzed polymerization of glycosyl fluorides derived from arabinoxylan oligosaccharides. $X$-ray diffraction and adsorption experiments on cellulosic surfaces revealed that the physicochemical properties of the synthetic polysaccharides strongly depend on the specific nature of their substitution patterns. The artificial polysaccharides allow structure-property relationship studies that are not accessible by other means.
\end{abstract}

Cellulose and xylan are the major polysaccharides in lignocellulosic biomass and as such are promising renewable resources for the production of materials and fuels. ${ }^{[1]}$ While

[*] D. Senf, Dr. C. Ruprecht, A. Matic, Dr. F. Pfrengle Department of Biomolecular Systems

Max Planck Institute of Colloids and Interfaces

Am Mühlenberg 1, 14476 Potsdam (Germany)

E-mail: Fabian.Pfrengle@mpikg.mpg.de

D. Senf, Dr. F. Pfrengle

Institute of Chemistry and Biochemistry

Freie Universität Berlin

Arnimallee 22, 14195 Berlin (Germany)

S. Kishani, Prof. Dr. L. Wågberg

Fibre and Polymer Technology

Royal Institute of Technology

Stockholm 10044 (Sweden)

and

Wallenberg Wood Science Center

KTH Royal Institute of Technology

Stockholm 10044 (Sweden)

A. Matic

Current address:

University of Potsdam, Department of Chemistry

Karl-Liebknecht-Strasse 24-25, 14476 Potsdam (Germany)

Prof. Dr. G. Toriz, Prof. Dr. P. Gatenholm

Wallenberg Wood Science Center and Biopolymer Technology

Department of Chemistry and Chemical Engineering

Chalmers University of Technology

Gothenburg 41296 (Sweden)

(1D)

Supporting information and the ORCID identification number(s) for the author(s) of this article can be found under:

https://doi.org/10.1002/anie.201806871. cellulose is regularly utilized for these purposes, the exploration of xylan lags behind because of its degree of structural complexity. ${ }^{[2]}$ In all higher plants xylans possess a backbone consisting of $\beta$-1,4-linked D-xylopyranoses and are decorated with arabinose, glucuronic acid, and acetyl groups (Figure 1).

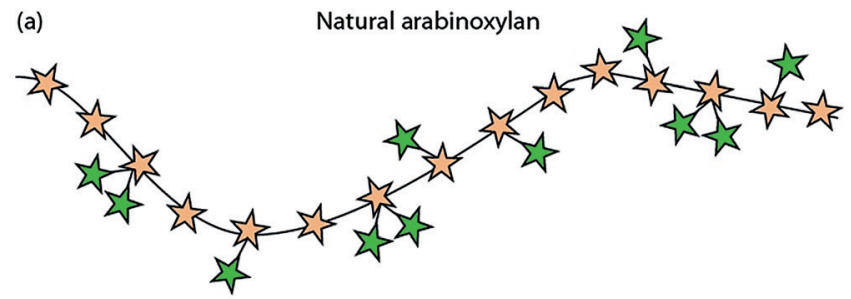

(b)

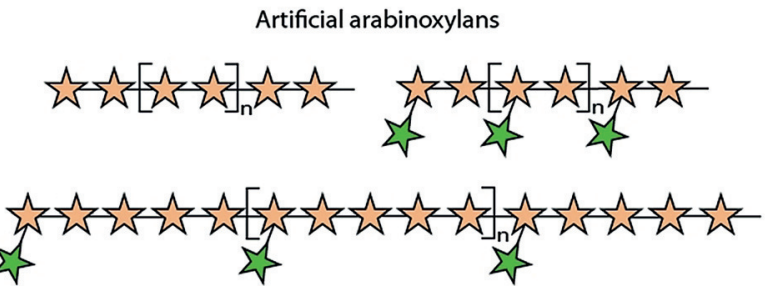

Figure 1. Schematic representation of a) a natural xylan with random branching pattern and b) artificial arabinoxylans with defined branching patterns.

The degree and type of substitution differs substantially among plant species. In grasses and cereals for instance, Larabinofuranose residues are the major substituents, while in soft- and hardwoods either D-glucuronic acids or its 4-Omethyl derivatives are mostly found. ${ }^{[3]}$ Xylans are used in the food industry as stabilizers, additives, and as ingredients in functional foods. ${ }^{[4]}$ Non-food applications range from their use as oxygen barrier films for packaging ${ }^{[5]}$ to strengtheners in paper production. ${ }^{[6]}$

The molecular composition of xylans has a strong impact on their macroscopic properties. A decrease in arabinose substitution is accompanied by a decrease in solubility ${ }^{[7]}$ and crystallinity as the substituents disrupt the interactions between individual xylan chains. ${ }^{[8]}$ Adsorption of xylan to cellulose also typically increases with lower degrees of substitution. ${ }^{[7,9]}$ Interestingly, the substitution pattern in glucuronoxylans is not random and recently it was shown by solid-state NMR spectroscopy of intact plant cell walls, ${ }^{[10]}$ and molecular dynamics simulations, ${ }^{[11]}$ that only xylan domains with evenly spaced substituents interact with the hydrophilic surface of cellulose microfibrils. This finding implies that the discrete substitution pattern in xylan strongly affects the 
ability of xylan to bind to cellulose, and determines the strength of the xylan-cellulose network in the cell wall and thus the strength of the respective plant material.

Detailed investigations into structure-property relationships of complex polysaccharides are hampered by their inhomogeneity as they are obtained by extraction from natural sources. Polysaccharides with defined branching patterns can only be obtained synthetically using a bottomup approach. Enzymatic polymerizations using glycosynthase $^{[12]}$ offer a fast and convenient synthetic route towards artificial polysaccharides. Glycosynthases are mutated glycosyl hydrolases in which the catalytic nucleophile in the active site is exchanged for a non-nucleophilic residue, thus inactivating the hydrolytic reaction. Instead, the enzyme irreversibly catalyzes the ligation of activated donors, such as $\alpha$ glycosyl fluorides, to suitable acceptor substrates, forming new glycosidic bonds. The yields provided by glycosynthases are generally higher than with the respective wild-type glycoside hydrolases. ${ }^{[7,9 a, 13]}$

When glycosynthases based on endo-glycosylases are used, the activated glycosyl donor acts as both the donor and acceptor, resulting in a polymerization reaction. In this way polysaccharides of different classes, ${ }^{[13 a, 14]}$ with molar masses up to $60 \mathrm{kDa}$, have been produced. ${ }^{[14 a, b, 15]}$ Xylanasederived glycosynthases have also been reported and used to synthesize homopolymers of xylan. ${ }^{[14 \mathrm{~d}-\mathrm{f}]}$ Substituted xylan polysaccharides have not been synthetically prepared. Herein, we present the synthesis of artificial arabinoxylan polysaccharides with defined branching patterns by glycosynthase-catalyzed polymerization of a number of different oligosaccharide fluorides.

To catalyze the polymerization of the arabinoxylan oligosaccharide fluorides, we chose the glycosynthase XynAE265G, which is able to produce xylan homopolymers containing more than 100 monosaccharide units. ${ }^{[14 d]}$ This glycosynthase is derived from a xylanase belonging to the glycoside hydrolase $(\mathrm{GH})$ family 10 (carbohydrate active enzyme database).$^{[16]} \mathrm{GH} 10$ xylanases typically release small oligosaccharides that carry arabinose substituents in the 2and/or 3-position of the nonreducing xylose residue as hydrolysis products from natural arabinoxylan polysaccharides. ${ }^{[17]}$ Based on this specificity, we designed seven arabinoxylan oligosaccharides (Figure 2) to serve as monomers for the polymerization reactions.

Xylobiose (1; Figure 2) and the $\alpha$-1,3-arabinofuranosylsubstituted xylan tri- and tetrasaccharides $\mathbf{2}$ and $\mathbf{3}$, respectively, were chemically synthesized following the same protecting-group strategy as we have used previously for the automated glycan assembly of arabinoxylan oligosacchari$\operatorname{des}^{[17 d, 18]}$ (see the Supporting Information). $\alpha$-1,2-Arabinofuranosyl- and $\alpha-1,2-\alpha-1,3$-arabinofuranosyl-disubstituted oligosaccharides $\mathbf{4}$ and $\mathbf{5}$, respectively, were procured in limited amounts commercially. Larger $\alpha-1,3$-arabinofuranosyl-substituted xylan oligosaccharides, 6 and 7, were obtained by a chemoenzymatic approach (Scheme 1) in which the arabinoxylan trisaccharide donor $\mathbf{1 3}$ was ligated to di- and trixyloside acceptors $\mathbf{1 4}$ and $\mathbf{1 5}$, respectively, using the glycosynthase XynAE265G. ${ }^{[14 \mathrm{~d}]}$ To prevent enzyme-catalyzed self-condensation, 13 was equipped with a tetrahydropyranyl (THP)
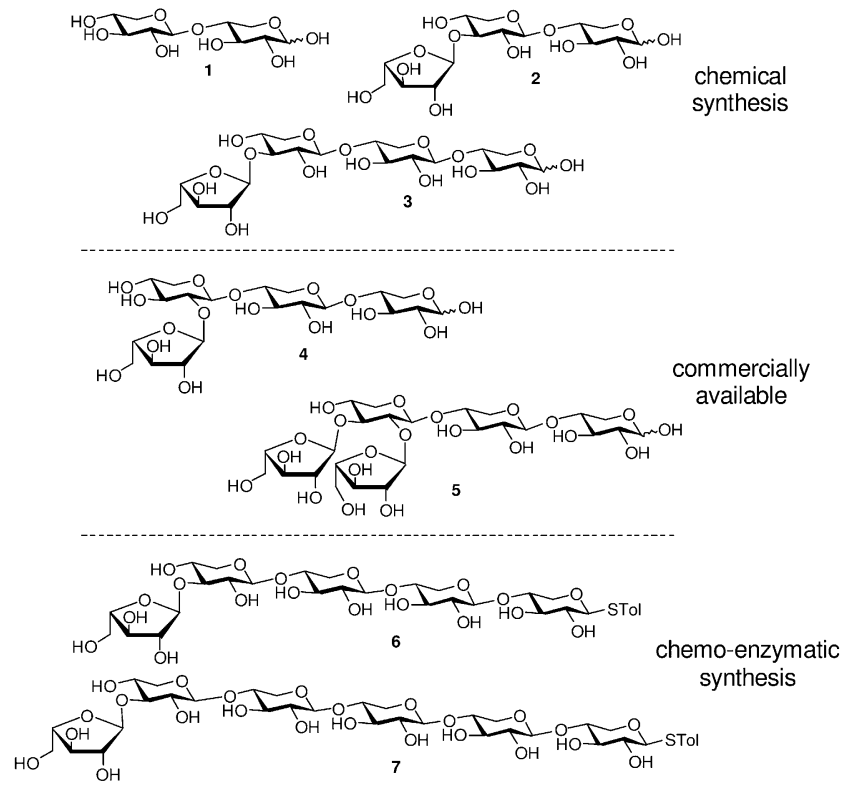

Figure 2. Oligosaccharide monomers for the synthesis of arabinoxylan polysaccharides. 1-3 and 6 and 7 were produced by chemical and chemoenzymatic synthesis, respectively. 4 and $\mathbf{5}$ were commercially available.

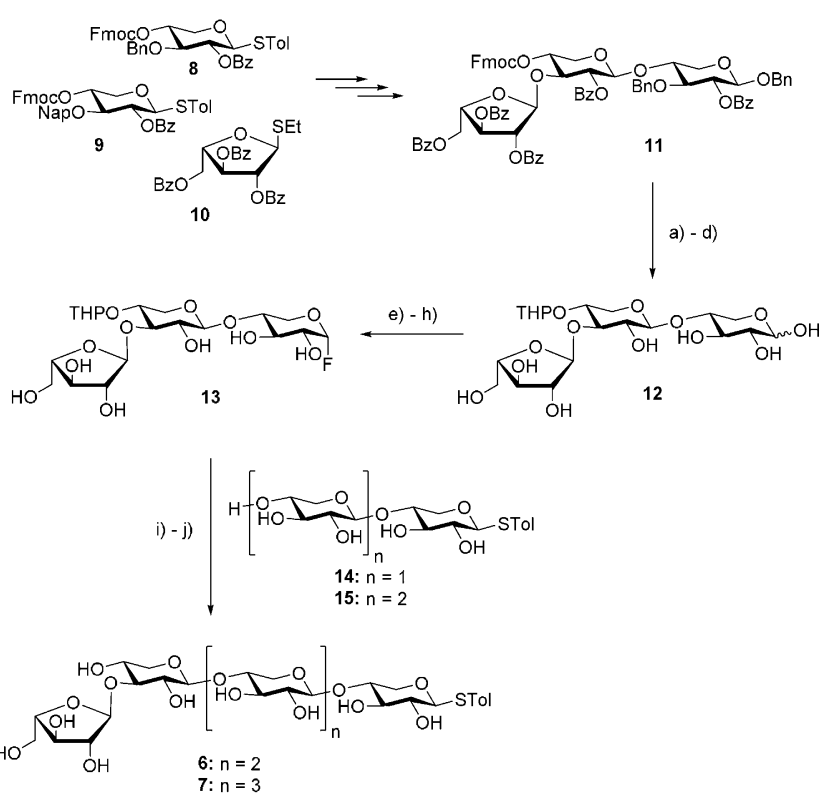

Scheme 1. Chemoenzymatic synthesis of the penta- and hexaarabinoxylosides 6 and 7, respectively. Reagents and conditions: a) $\mathrm{NEt}_{3}, \mathrm{DCM}$, 2 h, RT, 90\%; b) DHP, p-TsOH, DCM, 4 h, RT; c) $\mathrm{NaOMe}, \mathrm{MeOH} /$ $\operatorname{DCM}(3: 1), 16$ h, RT, $66 \%$ over 2 steps; d) $\mathrm{H}_{2}, \mathrm{Pd} / \mathrm{C}, \mathrm{MeOH} /$ EtOAc/ $\mathrm{Na}_{x} \mathrm{H}_{x} \mathrm{PO}_{4}$ buffer $(4: 1: 1), \mathrm{RT}, 24 \mathrm{~h}$; e) $\mathrm{Ac}_{2} \mathrm{O}, \mathrm{py}, 4 \mathrm{~h}, \mathrm{RT}$; f) HF/py, DCM $-30^{\circ} \mathrm{C} \rightarrow-20^{\circ} \mathrm{C}, 2 \mathrm{~h}, 60 \%$ over 3 steps; g) DHP, $p$-TsOH, DCM, $4 \mathrm{~h}$, RT, $91 \%$; h) NaOMe, $\mathrm{MeOH}, 0^{\circ} \mathrm{C}, 96 \%$; i) 14 or 15, XynAE265G, RT, $\mathrm{Na}_{x} \mathrm{H}_{x} \mathrm{PO}_{4}$ buffer, $16 \mathrm{~h}$; j) $1 \mathrm{M} \mathrm{HCl}, \mathrm{RT}, 30$ min, 6: 78\%, 7: $76 \%$ over 2 steps. For the synthesis of $\mathbf{1 4}$ and $\mathbf{1 5}$, see the Supporting Information. $\mathrm{Bz}=$ benzoyl, $\mathrm{DCM}=$ dichloromethane, Fmoc =9-fluorenylmethoxycarbonyl, Nap =2-naphthylmethyl, Ts = toluenesulfonyl.

ether in the C4-position of the nonreducing xylose residue. The THP group had successfully been used in the stepwise 
enzymatic synthesis of cellodextrins ${ }^{[19]}$ and xyloglucan oligosaccharides previously. ${ }^{[20]}$

The glycosyl donor $\mathbf{1 3}$ was prepared from the monosaccharide building blocks 8-10 (Scheme 1), which served as starting materials for the synthesis of the oligosaccharides $\mathbf{1}-$ 3. After assembly of the trisaccharide 11, the Fmoc-protecting group was exchanged by a THP-ether, and subsequent methanolysis of the benzoyl esters and hydrogenolysis of the benzyl ethers provided 4'-O-THP-protected trisaccharide 12. Peracetylation of $\mathbf{1 2}$ was then followed by fluorination with $\mathrm{HF} /$ pyridine at low temperature to provide the corresponding glycosyl fluoride. ${ }^{[21]}$ Reaction temperature and time were carefully adjusted to ensure formation of the thermodynamically favored $\alpha$-fluoride without cleavage of the rather acid-labile arabinofuranose substituent. The THP group did not stay intact under these reaction conditions and was subsequently reintroduced at the $\mathrm{C}^{\prime}$ '-position using 3,4dihydro- $2 \mathrm{H}$-pyran (DHP) and catalytic amounts of $p$ TsOH. ${ }^{[22]}$ Removal of the acetate groups by treatment with 1 equivalent of sodium methoxide at $0^{\circ} \mathrm{C}$ finally afforded $\mathbf{1 3}$. Overnight incubation of $\mathbf{1 3}$ with either the acceptor $\mathbf{1 4}$ or $\mathbf{1 5}$ and the glycosynthase XynAE265G, followed by removal of the THP protecting group, gave the desired penta- and hexasaccharides 6 and 7, respectively, in good yields. The thioether moiety in $\mathbf{6}$ and $\mathbf{7}$ provided a good hydrophobic handle for purification and permitted their later conversion into the corresponding glycosyl fluorides.

The conversion of the arabinoxylan oligosaccharides 1-7 into glycosyl fluorides 23-29 was performed by a three-step sequence consisting of peracetylation, fluorination, and deacetylation (Scheme 2). ${ }^{[21]}$ In the case of 16, 17, and 19, fluorination was performed using $\mathrm{HF} /$ pyridine at low temperature. Activation of the peracetylated oligosaccharides derived from 6 and 7 required the admixture of NIS to activate the thioether leaving group. ${ }^{[23]}$ A milder procedure was applied to the oligosaccharides $\mathbf{3}$ and $\mathbf{5}$, as the use of a larger excess of HF/pyridine provoked cleavage of the arabinofuranose. The hydroxy group at the anomeric center was selectively deprotected using hydrazine acetate first, and the resulting hydroxy group converted, with $N, N^{\prime}$-diethylaminosulfur trifluoride (DAST), into the corresponding $\beta$ fluoride. The $\beta$-fluorides were finally equilibrated into the desired $\alpha$-fluorides $\mathbf{2 5}$ and $\mathbf{2 7}$ using only small amounts of $\mathrm{HF} /$ pyridine. ${ }^{[24]}$

With the desired arabinoxylan glycosyl fluorides in hand, enzymatic polymerizations were performed by overnight incubation of the respective glycosyl fluoride with XynAE265G, and arabinoxylan polysaccharides in amounts of up to $55 \mathrm{mg}(\mathbf{3 1})$ in one batch were obtained (Scheme 3). In some cases, precipitates of water-insoluble polysaccharides $(30 \mathbf{a}, 32 \mathbf{a}$, and 33a) were formed during the reactions, whereas in the other cases the reaction products remained fully soluble. When precipitated polysaccharides were formed, they were collected by centrifugation and the remaining solution was passed through a short C18 cartridge to isolate the soluble polysaccharide fraction $(\mathbf{3 0} \mathbf{b}, \mathbf{3 2} \mathbf{b}$, and 33b). Water-soluble polysaccharide products were directly subjected to $\mathrm{C} 18$ reversed-phase chromatography. MALDI mass spectrometry was used to confirm the formation of oligomers of the starting oligosaccharides (see the Supporting Information). Further conformation was obtained by digestion of the synthetic polysaccharides with xylanases, ${ }^{[25]}$ which resulted, unlike in the case of natural rye arabinoxylan, in the formation of very simple and defined hydrolysis products, a fact that may be exploited for determining the substrate specificity of newly discovered xylan-degrading enzymes (see the Supporting Information). The molecular mass distribution of the products was derived from high-performance sizeexclusion chromatography (HPSEC) calibrated with pullulan standards (Figure 2) since it cannot be deduced from mass
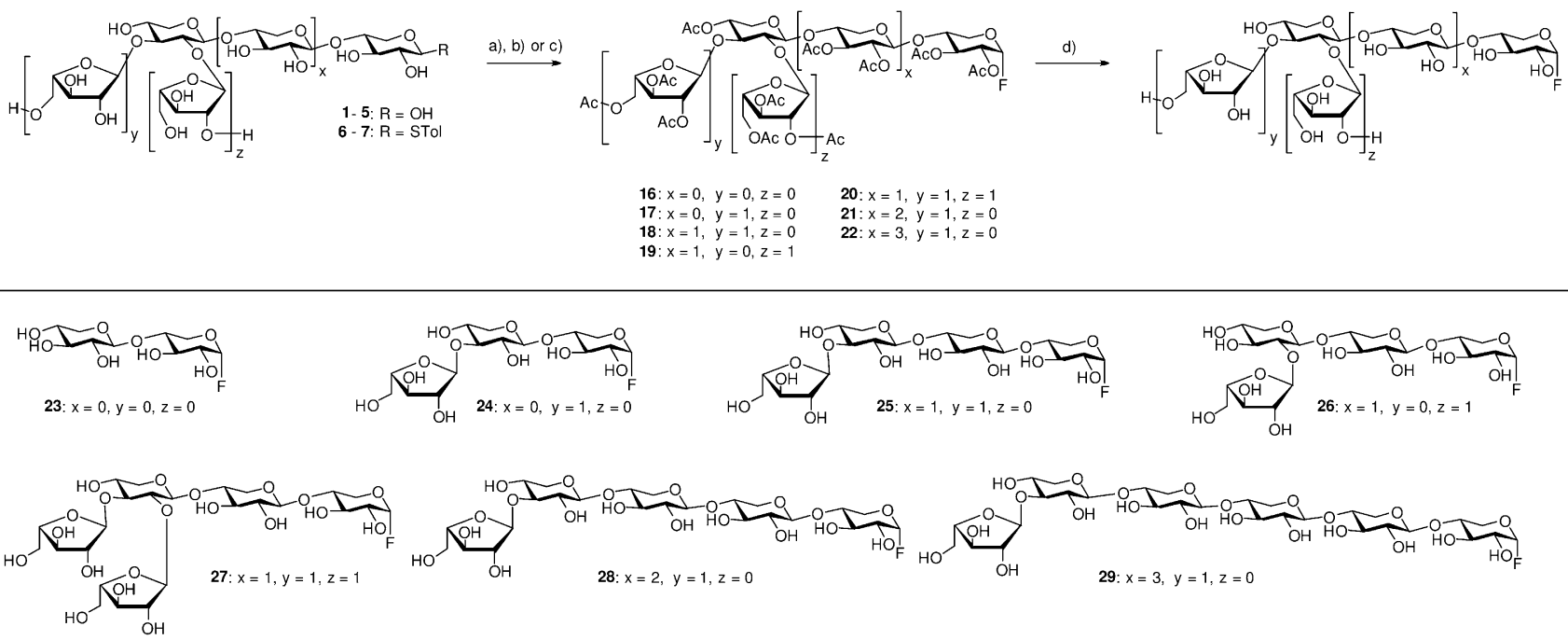

Scheme 2. Synthesis glycosyl fluoride donors $23-29$. Reagents and conditions: a) $\mathrm{Ac}_{2} \mathrm{O}, \mathrm{py}, \mathrm{RT}$; b) for 16,17, and $19: \mathrm{HF} / \mathrm{py},-30^{\circ} \mathrm{C} \rightarrow-20^{\circ} \mathrm{C}$ or $-10^{\circ} \mathrm{C}, 2-5 \mathrm{~h}$, for 18 and 20 : i) $\mathrm{N}_{2} \mathrm{H}_{4} \cdot \mathrm{AcOH}, \mathrm{DMF}, 0^{\circ} \mathrm{C}, 5 \mathrm{~h}$, ii) DAST, DCM, $0{ }^{\circ} \mathrm{C}, 1 \mathrm{~h}$, then $\left.\mathrm{HF} / \mathrm{py}, \mathrm{DCM},-30^{\circ} \mathrm{C} \rightarrow 10^{\circ} \mathrm{C}, 2-5 \mathrm{~h}, \mathrm{C}\right) \mathrm{NIS}, \mathrm{cat} . \mathrm{HF} /$ py, $-50^{\circ} \mathrm{C}$ (for 21 and 22 only), then HF/py, DCM, $-30^{\circ} \mathrm{C} \rightarrow-10^{\circ} \mathrm{C}, 2-5 \mathrm{~h}, 16: 79 \%, 17: 89 \%$; 18: $77 \%$ over 3 steps, 19: $43 \%, 20: 44 \%$ over 3 steps, 21: $53 \%$ over 2 steps, 22: $52 \%$ over 2 steps; h) $\mathrm{NaOMe}, \mathrm{MeOH}, 0^{\circ} \mathrm{C}, 23$ : quant., 24: quant.; 25: quant., 26: quant., 27: $96 \%$, 28: $99 \%$, 29: quant. $\mathrm{DMF}=\mathrm{N}, \mathrm{N}$-dimethylformamide, $\mathrm{NIS}=\mathrm{N}$-iodosuccinimide, $\mathrm{py}=$ pyridine. 


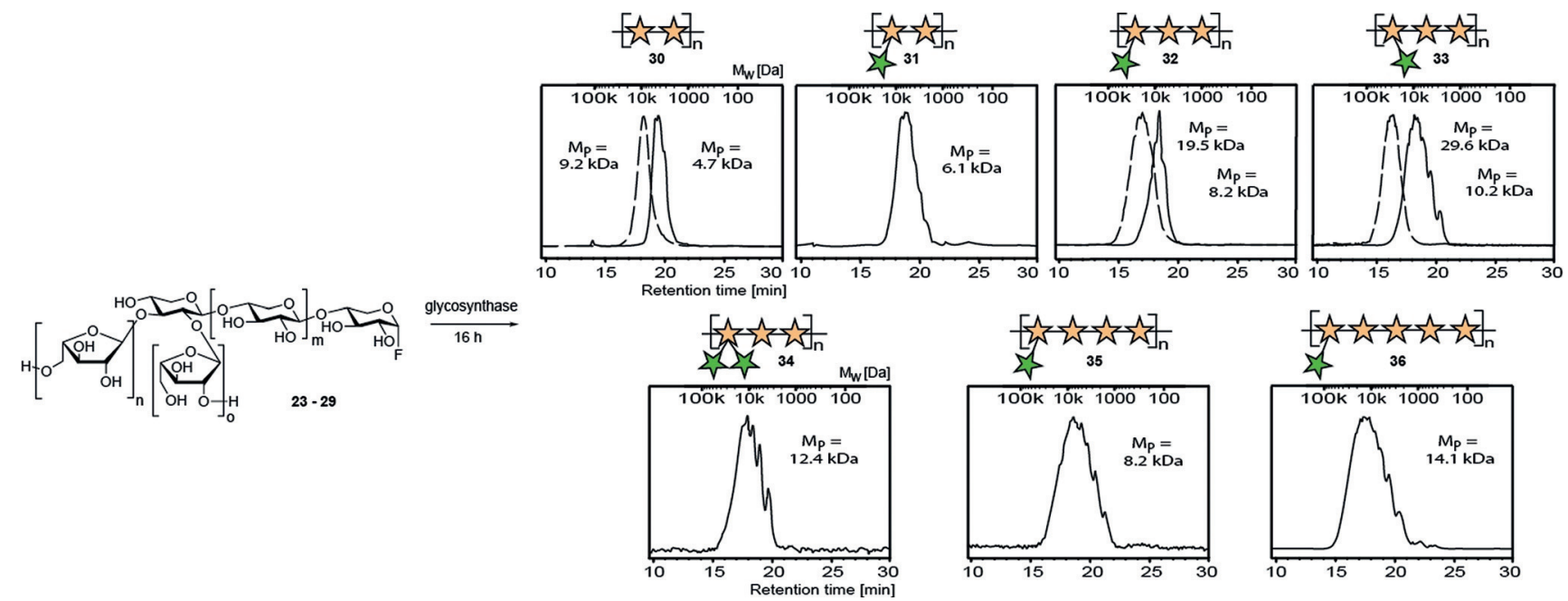

Scheme 3. Synthesis of artificial arabinoxylan polysaccharides by enzymatic polymerization of arabinoxylan oligosaccharide fluorides. The molecular mass distribution of the resulting polysaccharides was analyzed by HPSEC chromatography using a TSK gel 3000 column and an ELSdetector. Chromatograms with two ELSD traces were obtained when a water-insoluble polysaccharide fraction (dashed line, 30a, 32a, and 33a) and a water-soluble fraction (solid line, 30b, 32b, and 33b) was obtained. These fractions were analyzed separately.

spectrometry experiments because of the size-dependent molecule desorption from the MALDI matrix. ${ }^{[26]}$ We found that the molecular weight at the peak maximum $\left(M_{P}\right)$ of the different polysaccharide products ranged from $4.7 \mathrm{kDa}$ for the water-soluble fraction of linear xylan $\mathbf{3 0}$ to $29.6 \mathrm{kDa}$ for the water-insoluble fraction of arabinoxylan $\mathbf{3 3}$. These values correspond to $36(n=18)$ and $224(n=56)$ monosaccharides, respectively. The observed differences in the degree of polymerization (DP) of the artificial polysaccharides are most likely a result of the substrate specificity of the enzyme that transfers some of the arabinoxylan oligosaccharides more efficiently than others.

There is an inherent limitation for the maximum achievable lengths of the synthetic xylan polysaccharides and it is determined by their solubility. Thus, the $M_{p}$ of the linear xylan polysaccharide 30, for example, did not exceed $9.2 \mathrm{kDa}$. Besides for the linear xylan, water-insoluble polysaccharide fractions were obtained for the arabinoxylans $\mathbf{3 2}$ and $\mathbf{3 3}$ which carry the arabinofuranosyl substituents at the 2- and 3position, respectively, of every third xylose residue. In line with this, for $\mathbf{3 2}$ and $\mathbf{3 3}$ significant crystallinity was observed, whereas for $\mathbf{3 1}, \mathbf{3 5}$, and $\mathbf{3 6}$, as well as natural rye arabinoxylan, were completely amorphous, as qualitatively determined by $\mathrm{X}$-ray diffraction (Figure $3 \mathrm{a}$ ). The specific substitution pattern of $\mathbf{3 2}$ and $\mathbf{3 3}$ might favor a stable threefold helical screw conformation, with the substituents all pointing in the same direction. ${ }^{[27]}$ Such a conformation would enable interactions between the xylan backbones of individual molecules, explaining the low solubility and the crystallinity of $\mathbf{3 2}$ and 33. This observation contradicts the commonly accepted notion that solubility and crystallinity of xylans directly correspond with the degree of substitution. ${ }^{[7,9 a]}$

Recent studies show that in intact plant cell walls xylan partially flattens from the typical threefold helical screw into a twofold helical screw ribbon to enable intimate binding to cellulose microfibrils. ${ }^{[10 a, 11,28]}$ An even pattern of xylan
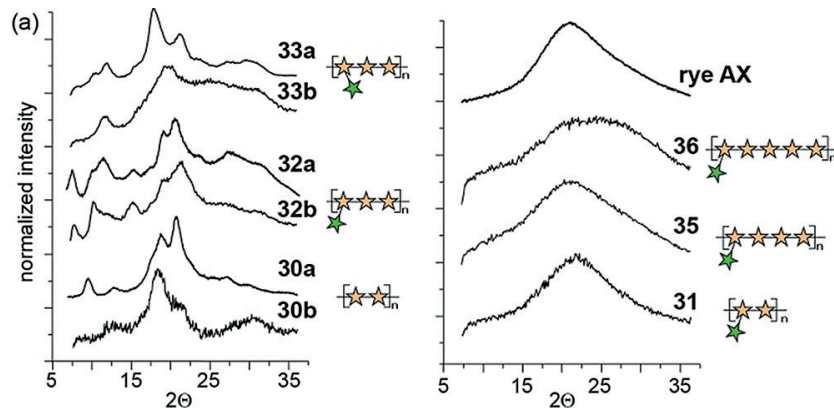

(b)
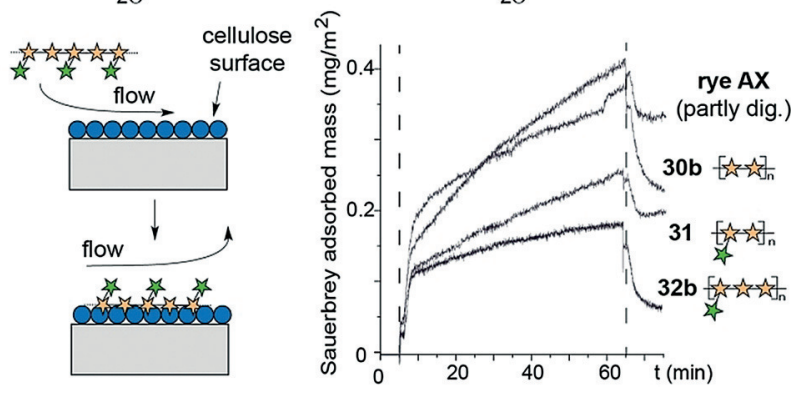

Figure 3. a) Influence of the arabinose substitution patterns of the synthetic polysaccharides on crystallinity as determined by X-ray diffraction. rye $\mathbf{A X}=$ rye arabinoxylan. b) Adsorbed amounts $\left(\mathrm{g} \mathrm{m}^{-2}\right.$; including immobilized water) of $\mathbf{3 0 b}, \mathbf{3 1}, \mathbf{3 2} \mathrm{b}$, and partly digested rye arabinoxylan $\left(\mathrm{M}_{\mathrm{P}}=5.5 \mathrm{kDa}\right)$ on spin-coated model cellulose surfaces, as determined by QCM-D.

substitution with acetyl and/or glucuronic acid residues appears to be essential for this interaction to occur, and consequently for the development of normal plant secondary cell walls. ${ }^{[29]}$ In order to study the ability of synthetic xylan polysaccharides 30-32 to adsorb and bind to cellulose, we performed QCM-D experiments on spin-coated cellulose surfaces (Figure $3 \mathrm{~b}$ ). As expected, the unsubstituted xylan 30 showed the highest adsorption of the synthetic polysaccha- 
rides to the cellulose surface. More interestingly, we observed that the arabinoxylan $\mathbf{3 1}$ adsorbed irreversibly, that is, only a minor desorption, upon rinsing, to the cellulose surface while the water-soluble fraction of $\mathbf{3 2}$, despite the fact that it is less substituted, only adsorbed weakly with a large desorption upon rinsing (both polysaccharides having similar molecular weights). Since both these polymers should have similar driving forces for their adsorption, this result indicates that once adsorbed, $\mathbf{3 1}$ has experienced a conformational change from a threefold to a twofold helical screw, permitting strong interactions between $\mathbf{3 1}$ and the cellulose surface. Unlike $\mathbf{3 1}$, 32 cannot adopt a twofold helical screw conformation with the substituents all pointing in the same direction. Natural rye arabinoxylan, which was enzymatically hydrolyzed to a similar size as the synthetic xylan polysaccharides, showed stronger adsorption properties than $\mathbf{3 2}$ (more comparable to synthetic xylan 30), indicating that it does not contain large amounts of unevenly substituted xylan domains.

Our study provides direct support by physical in vitro experiments outside the cell wall for the observation that specific substitution patterns are required for strong xylancellulose interactions and the first hint that, besides acetylation and substitution by glucuronic acid, also the patterning of arabinose substituents on the xylan backbone may be relevant. These interactions influence both strength and digestibility of plant cell walls.

In summary, we have explored glycosynthase technology for the polymerization of seven, mostly chemically synthesized, arabinoxylan oligosaccharides into artificial polysaccharides with well-defined branching patterns. The obtained polysaccharides contained polysaccharide chains with molecular masses of up to $80 \mathrm{kDa}$ (606 monosaccharides), which are to the best of our knowledge the largest polysaccharides produced by glycosynthase technology to date. Because of the defined nature of the polysaccharide branching patterns, specific properties were observed for particular members of the prepared arabinoxylan collection rather than the simple linear correlation between, for example, crystallinity and degree of substitution reported previously. ${ }^{[9 a]}$ Currently, we are evaluating their immunomodulatory properties ${ }^{[30]}$ as well as their potential to serve as substrates in assays aimed at determining the specificities of xylan-degrading enzymes. ${ }^{[25 b, c]}$

\section{Acknowledgements}

We gratefully acknowledge financial support from the Max Planck Society and the German Research Foundation (DFG, Emmy Noether program PF850/1-1 to FP and SFB 765). The Knut and Alice Wallenberg Foundation is acknowledged for funding the Wallenberg Wood Science Center. We thank Maiko Schulze and Suvrat Chowdhary for experimental help. We thank Ingrid Zenke for recording X-ray diffractograms and Janete Rodriguez and Dr. Luca Bertinetti for helpful discussions. The plasmid for expression of XynAE265G was kindly provided by Prof. Dr. Yuval Shoham (TechnionIsrael Institute of Technology).

\section{Conflict of interest}

The authors declare no conflict of interest.

Keywords: carbohydrates · enzymes · glycosynthases . structure elucidation $\cdot$ synthetic methods

How to cite: Angew. Chem. Int. Ed. 2018, 57, 11987-11992 Angew. Chem. 2018, 130, 12163-12168

[1] J. Song, C. Chen, S. Zhu, M. Zhu, J. Dai, U. Ray, Y. Li, Y. Kuang, Y. Li, N. Quispe, Y. Yao, A. Gong, U. H. Leiste, H. A. Bruck, J. Y. Zhu, A. Vellore, H. Li, M. L. Minus, Z. Jia, A. Martini, T. Li, L. Hu, Nature 2018, 554, 224.

[2] a) E. A. Rennie, H. V. Scheller, Curr. Opin. Biotechnol. 2014, 26, $100-107$; b) H. V. Scheller, P. Ulvskov, Annu. Rev. Plant Biol. 2010, 61, 263-289.

[3] a) A. Ebringerová, T. Heinze, Macromol. Rapid Commun. 2000, 21, 542-556; b) A. Ebringerová, Z. Hromádková, T. Heinze in Polysaccharides I, Vol. 186 (Ed.: T. Heinze), Springer, Berlin, 2005, pp. 1-67.

[4] a) A. M. Neyrinck, V. F. Van Hee, N. Piront, F. De Backer, O. Toussaint, P. D. Cani, N. M. Delzenne, Nutr. Diabetes 2012, 2, e28; b) M. Mendis, E. Leclerc, S. Simsek, Carbohydr. Polym. 2016, 139, 159-166; c) J. Liu, S. Willför, C. Xu, Bioact. Carbohydr. Dietary Fibre 2015, 5, 31-61.

[5] a) N. M. L. Hansen, D. Plackett, Biomacromolecules 2008, 9, 1493-1505; b) A. Escalante, A. Gonçalves, A. Bodin, A. Stepan, C. Sandström, G. Toriz, P. Gatenholm, Carbohydr. Polym. 2012, $87,2381-2387$.

[6] A. L. Deutschle, K. Römhild, F. Meister, R. Janzon, C. Riegert, B. Saake, Carbohydr. Polym. 2014, 102, 627-635.

[7] T. Köhnke, Å. Östlund, H. Brelid, Biomacromolecules 2011, 12, $2633-2641$

[8] K. A. Andrewartha, D. R. Phillips, B. A. Stone, Carbohydr. Res. 1979, 77, 191-204.

[9] a) T. J. Bosmans, A. M. Stépán, G. Toriz, S. Renneckar, E. Karabulut, L. Wågberg, P. Gatenholm, Biomacromolecules 2014 , 15, 924-930; b) A. Linder, R. Bergman, A. Bodin, P. Gatenholm, Langmuir 2003, 19, 5072-5077; c) M. A. Kabel, H. van den Borne, J.-P. Vincken, A. G. J. Voragen, H. A. Schols, Carbohydr. Polym. 2007, 69, 94-105.

[10] a) T. J. Simmons, J. C. Mortimer, O. D. Bernardinelli, A.-C. Pöppler, S. P. Brown, E. R. deAzevedo, R. Dupree, P. Dupree, Nat. Commun. 2016, 7, 13902; b) A. Martínez-Abad, J. Berglund, G. Toriz, P. Gatenholm, G. Henriksson, M. Lindström, J. Wohlert, F. Vilaplana, Plant Physiol. 2017, O, 0.

[11] M. Busse-Wicher, A. Li, R. L. Silveira, C. S. Pereira, T. Tryfona, T. C. F. Gomes, M. S. Skaf, P. Dupree, Plant Physiol. 2016, 171, 2418.

[12] L. F. Mackenzie, Q. Wang, R. A. J. Warren, S. G. Withers, J. Am. Chem. Soc. 1998, 120, 5583-5584.

[13] a) L.-X. Wang, W. Huang, Curr. Opin. Chem. Biol. 2009, 13, $592-600$; b) P. M. Danby, S. G. Withers, ACS Chem. Biol. 2016, 11, 1784-1794.

[14] a) O. Spadiut, F. M. Ibatullin, J. Peart, F. Gullfot, C. MartinezFleites, M. Ruda, C. Xu, G. Sundqvist, G. J. Davies, H. Brumer, J. Am. Chem. Soc. 2011, 133, 10892-10900; b) X. Pérez, M. Faijes, A. Planas, Biomacromolecules 2011, 12, 494-501; c) M. Faijes, A. Planas, Carbohydr. Res. 2007, 342, 1581-1594; d) A. BenDavid, T. Bravman, Y. S. Balazs, M. Czjzek, D. Schomburg, G. Shoham, Y. Shoham, ChemBioChem 2007, 8, 2145-2151; e) Y.W. Kim, D. T. Fox, O. Hekmat, T. Kantner, L. P. McIntosh, R. A. J. Warren, S. G. Withers, Org. Biomol. Chem. 2006, 4, 2025-2032; f) M. Sugimura, M. Nishimoto, M. Kitaoka, Biosci. Biotechnol. Biochem. 2006, 70, 1210-1217; g) B. Cobucci- 
Ponzano, M. Moracci, Nat. Prod. Rep. 2012, 29, 697-709; h) S. Fort, V. Boyer, L. Greffe, G. J. Davies, O. Moroz, L. Christiansen, M. Schülein, S. Cottaz, H. Driguez, J. Am. Chem. Soc. 2000, $122,5429-5437$.

[15] F. Gullfot, F. M. Ibatullin, G. Sundqvist, G. J. Davies, H. Brumer, Biomacromolecules 2009, 10, 1782-1788.

[16] a) V. Lombard, H. Golaconda Ramulu, E. Drula, P. M. Coutinho, B. Henrissat, Nucleic Acids Res. 2014, 42, D490-D495; b) T. Bravman, V. Belakhov, D. Solomon, G. Shoham, B. Henrissat, T. Baasov, Y. Shoham, J. Biol. Chem. 2003, 278 , $26742-26749$.

[17] a) S. L. Maslen, F. Goubet, A. Adam, P. Dupree, E. Stephens, Carbohydr. Res. 2007, 342, 724-735; b) M. Vardakou, P. Katapodis, M. Samiotaki, D. Kekos, G. Panayotou, P. Christakopoulos, Int. J. Biol. Macromol. 2003, 33, 129-134; c) P. Biely, M. Vršanská, M. Tenkanen, D. Kluepfel, J. Biotechnol. 1997, 57, 151-166; d) D. Senf, C. Ruprecht, G. H. M. deKruijff, S. O. Simonetti, F. Schuhmacher, P. H. Seeberger, F. Pfrengle, Chem. Eur. J. 2017, 23, 3197-3205.

[18] a) D. Schmidt, F. Schuhmacher, A. Geissner, P. H. Seeberger, F Pfrengle, Chem. Eur. J. 2015, 21, 5709-5713; b) F. Pfrengle, Curr. Opin. Chem. Biol. 2017, 40, 145-151.

[19] S. Fort, L. Christiansen, M. Schülein, S. Cottaz, H. Drigueza, Isr. J. Chem. 2000, 40, 217-221.

[20] R. Fauré, M. Saura-Valls, H. Brumer, A. Planas, S. Cottaz, H. Driguez, J. Org. Chem. 2006, 71, 5151-5161.

[21] a) M. Yokoyama, Carbohydr. Res. 2000, 327, 5-14; b) M. Shimizu, H. Togo, M. Yokoyama, Synthesis 1998, 799-822; c) J. Jünnemann, J. Thiem, C. Pedersen, Carbohydr. Res. 1993,
249, 91 -94; d) P. J. Card, J. Carbohydr. Chem. 1985, 4, 451-487; e) M. Hayashi, S.-i. Hashimoto, R. Noyori, Chem. Lett. 1984, 13, $1747-1750$.

[22] A. Bongini, G. Cardillo, M. Orena, S. Sandri, Synthesis 1979, $618-620$

[23] A. Steinmann, J. Thimm, M. Matwiejuk, J. Thiem, Macromolecules 2010, 43, 3606-3612.

[24] G. H. Posner, S. R. Haines, Tetrahedron Lett. 1985, 26, 5-8.

[25] a) S. Lagaert, A. Pollet, C. M. Courtin, G. Volckaert, Biotechnol. Adv. 2014, 32, 316-332; b) A. Pollet, J. A. Delcour, C. M. Courtin, Crit. Rev. Biotechnol. 2010, 30, 176-191; c) T. Collins, C. Gerday, G. Feller, FEMS Microbiol. Rev. 2005, 29, 3-23.

[26] a) D. C. Schriemer, L. Li, Anal. Chem. 1997, 69, 4176-4183; b) M. W. F. Nielen, S. Malucha, Rapid Commun. Mass Spectrom. 1997, 11, 1194-1204.

[27] I. Nieduszynski, R. H. Marchessault, Nature 1971, 232, 46-47.

[28] M. Busse-Wicher, T. C. F. Gomes, T. Tryfona, N. Nikolovski, K. Stott, N. J. Grantham, D. N. Bolam, M. S. Skaf, P. Dupree, Plant J. 2014, 79, 492-506.

[29] N. J. Grantham, J. Wurman-Rodrich, O. M. Terrett, J. J. Lyczakowski, K. Stott, D. Iuga, T. J. Simmons, M. Durand-Tardif, S. P. Brown, R. Dupree, M. Busse-Wicher, P. Dupree, Nat. Plants 2017, 3, 859-865.

[30] A. Proksch, H. Wagner, Phytochemistry 1987, 26, 1989-1993.

Manuscript received: June 14, 2018

Accepted manuscript online: July 25, 2018

Version of record online: August 19, 2018 